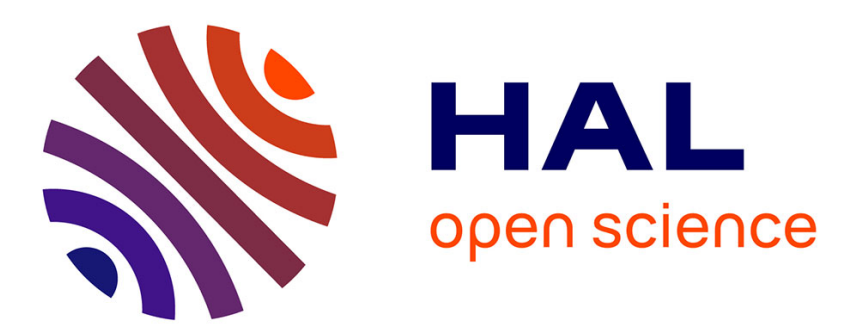

\title{
Training in Decision-Making Strategies: An Approach to Enhance Students' Competence to Deal with Socioscientific Issues
}

\author{
Helge Gresch, Marcus Hasselhorn, Susanne Bögeholz
}

\section{- To cite this version:}

Helge Gresch, Marcus Hasselhorn, Susanne Bögeholz. Training in Decision-Making Strategies: An Approach to Enhance Students' Competence to Deal with Socioscientific Issues. International Journal of Science Education, 2011, pp.1. 10.1080/09500693.2011.617789 . hal-00738304

\author{
HAL Id: hal-00738304 \\ https://hal.science/hal-00738304
}

Submitted on 4 Oct 2012

HAL is a multi-disciplinary open access archive for the deposit and dissemination of scientific research documents, whether they are published or not. The documents may come from teaching and research institutions in France or abroad, or from public or private research centers.
L'archive ouverte pluridisciplinaire HAL, est destinée au dépôt et à la diffusion de documents scientifiques de niveau recherche, publiés ou non, émanant des établissements d'enseignement et de recherche français ou étrangers, des laboratoires publics ou privés. 

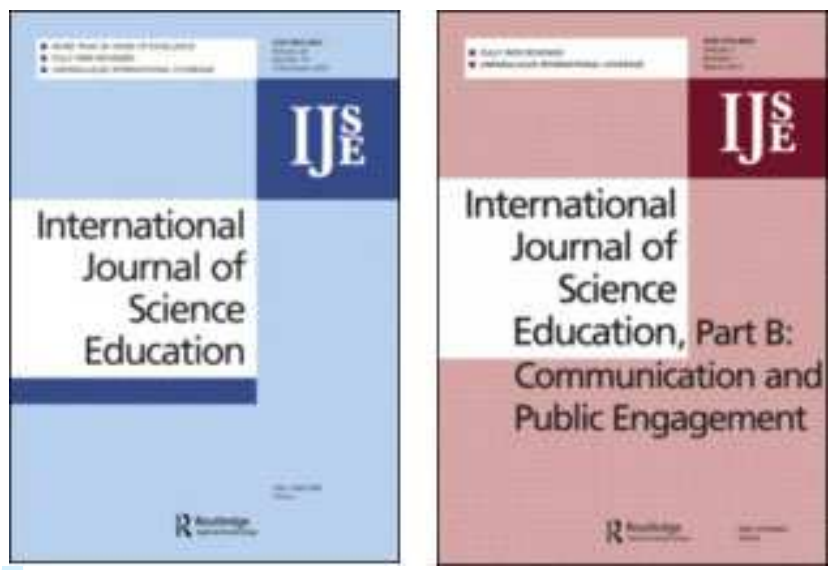

Training in Decision-Making Strategies: An Approach to Enhance Students' Competence to Deal with Socioscientific Issues

\begin{tabular}{|r|l|}
\hline Journal: & International Journal of Science Education \\
\hline Manuscript ID: & TSED-2011-0179-A.R3 \\
\hline Manuscript Type: & Research Paper \\
\hline Keywords: & science, technology, society, environmental education \\
\hline Keywords (user): & $\begin{array}{l}\text { decision-making, socio-scientific issues, education for sustainable } \\
\text { development }\end{array}$ \\
\hline
\end{tabular}

\section{SCHOLARONE Manuscripts}




\title{
Training in Decision-Making Strategies: An Approach to Enhance Students' Competence to Deal with Socioscientific Issues
}

\begin{abstract}
Dealing with socioscientific issues in science classes enables students to participate productively in controversial discussions concerning ethical topics such as sustainable development. In this respect, well-structured decision-making processes are essential for elaborate reasoning. To foster decision-making competence, a computerbased programme was developed that trains secondary school students (grades 11-13) in decision-making strategies. The main research question is: does training students to use these strategies foster decision-making competence? In addition, the influence of metadecision aids was examined. Students conducted a task analysis to select an appropriate strategy prior to the decision-making process. Hence, the second research question is: does combining decision-making training with a task analysis enhance decision-making competence at a higher rate? To answer these questions, 386 students were tested in a pre-post-follow-up control-group design that included two training groups (decision-making strategies/decision-making strategies combined with a task analysis) and a control group (decision-making with additional ecological information instead of strategic training). An open-ended questionnaire was used to assess decision-making competence in situations related to sustainable development. The decision-making training led to a significant improvement in the post-test and the follow-up, which was administered three months after the training. Long-term effects on the quality of the students' decisions were evident for both training groups. Gains in competence when reflecting upon the decision-making processes of others were found,
\end{abstract}


to a lesser extent, in the training group that received the additional metadecision training. In conclusion, training in decision-making strategies is a promising approach to deal with socioscientific issues related to sustainable development.

Keywords: decision-making; socioscientific issues; science, technology, society, environment (STSE); education for sustainable development; environmental education

\section{Introduction}

Controversial discussions about socioscientific issues require students to understand complex scientific and ethical issues (Zeidler, Sadler, Simmons \& Howes, 2005). A central aim of science education is to teach students to be critical thinkers and participatory citizens who are capable of making well-informed and systematic decisions. Moreover, dealing with socioscientific issues has become an essential part of scientific literacy and has therefore been included in various standards and curricula (American Association for the Advancement of Science [AAAS], 1989; Kultusministerkonferenz [KMK], 2005; National Research Council [NRC], 1996; Zeidler et al., 2005). One crucial topic in the field of socioscientific issues is the sustainable development of our environment (Bögeholz, Hößle, Langlet, Sander \& Schlüter, 2004; Pedretti, 2003; Ratcliffe \& Grace, 2003). Sustainable development provides natural resources and welfare for today's society as well as for future generations. Decisions about sustainability issues are complex and include a wide range of possible courses of action. As a result, decision-making competence is a core component of education for sustainable development and environmental education (Arvai, Campbell, Baird \& Rivers, 2004; de Haan, 2010; Eggert \& Bögeholz, 2006). 
Because socioscientific issues concerning sustainable development are not fully integrated into science education, new methods of approaching these topics must be developed. Which classroom activities are useful for fostering informed decisionmaking? The central purpose of this study is to investigate whether training in the use of decision-making strategies contributes to systematic and elaborate reasoning in the field of sustainability issues. A second goal is to determine whether metadecision aids, which are based on the framework of self-regulated learning, enhance the decisionmaking process at a higher rate.

\section{Theoretical Framework}

\section{Socioscientific Issues and Education for Sustainable Development}

Socioscientific issues are controversial scientific topics that involve social and ethical considerations (Sadler, 2004; Zeidler \& Sadler, 2007; Zeidler et al., 2005). They are complex and ill-structured real-world problems for which a definite solution does not exist (Sadler, 2004). In addition to complex scientific evidence, normative considerations and personal values must be taken into account when constructing moral judgments (Bögeholz \& Barkmann, 2005; Jiménez-Aleixandre \& Pereiro-Muñoz, 2002; Kolstø, 2001; Ratcliffe \& Grace, 2003; Zeidler \& Sadler, 2007).

Much research has been done on the structure of argumentation, characteristics of a good argument and fallacies in reasoning (Driver, Newton \& Osborne, 2000; Kuhn, 1991; Sadler \& Zeidler, 2005; Zeidler, 1997; Zohar \& Nemet, 2002). However, before a student can justify his/her position, the student must decide which position is best. 
Therefore, the individual decision-making process is a necessary prerequisite for argumentation and discourse.

One vital domain of socioscientific issues is sustainable development. Since the publication of the Agenda 21 (UNCED, 1992), social and economic aspects of development policies are supposed to be considered along with environmental concerns. These three domains of sustainable development (social, economic and ecological) and their interdependencies have become the fundamental bases of action plans and education for sustainable development (de Haan, 2010; Huckle \& Sterling, 1996; Sauvé, 1996; Scott \& Gough, 2003).

The concept of sustainable development has been incorporated into standards and curricula to different extents. The AAAS (1989) and the US National Science Education Standards (NRC, 1996) include resource management and the protection of the environment. In addition, German and English national standards (KMK, 2005; KMK \& BMZ, 2007; QCA, 2004) emphasise the need for education for sustainable development.

\section{Decision-Making Strategies}

Behavioural decision research aims to describe and explain the judgment and decision-making processes in order to improve decision-making behaviour (Payne, Bettmann \& Luce, 1998). Before relating this descriptive approach to the normative aspects of decision-making in education for sustainable development, three models that describe actual decision-making behaviour will be presented (Jungermann, Pfister \& Fischer, 2005; Payne et al., 1998). 
Decision-making situations often consist of a set of possible options that can be described with regard to different criteria relevant for the decision-making process. A full trade-off of all the given information can best be described by the weighted-additivevalue model (Jungermann et al., 2005; Payne et al., 1998). In this model, all of the available information is used to evaluate the overall quality of each option. Furthermore, important criteria will affect the decision more than less important criteria. This model assumes that there are equally legitimate options and that a decision-maker takes all information into account. Although this model dominated the behavioural decision research, various other models have been developed.

In contrast with a compensatory strategy, in which benefits and drawbacks compensate one another (Jungermann et al., 2005), non-compensatory strategies describe a decision-making behaviour, where unacceptable options are eliminated. Therefore, the disadvantages are not compensated for by other advantages. According to the elimination-by-aspects model (Jungermann et al., 2005; Payne et al., 1998), options are excluded if they do not meet a minimum cut-off threshold with respect to the most important criterion. Subsequently, the second most important criterion is used to exclude further options. This process is repeated until only one option remains.

Frequently, decision-making strategies are combined to reach a conclusion. In his image theory, Beach (1990) describes a screening phase in which unacceptable options are excluded before an in-depth analysis of the remaining options, including full trade-offs, is performed.

Payne et al. (1998) claim that decisions that are entirely or partly based on noncompensatory procedures are grounded in rational considerations to some extent, but 
are also based upon heuristics that were used to simplify the decision. In the context of moral judgment, Haidt (2001) goes one step further by stating that most ethical decisions are primarily based on intuitions rather than rational considerations. According to his social-intuitionist model, reasoning is usually a post-hoc construction used to justify the initial judgment. Although actual decision-making processes may be intuitive and may lead to satisfying results in routine decisions, Haidt (2001), Arvai et al. (2004) and Eggert and Bögeholz (2006) acknowledge that intuitional decisions are not considered the best from a normative viewpoint for all types of decisions. Baron (1998) states that intuitive decisions may even have disastrous consequences. This is especially true in complex decision-making situations, such as those concerning sustainable development, in which a systematic decision is considered more appropriate than one based on heuristics (Arvai et al., 2004; Eggert \& Bögeholz, 2006). However, models that describe actual decision-making behaviour may help educators to design learning environments that help students improve their decision-making processes (Haidt, 2001; Payne et al., 1998).

Considering socioscientific issues, decision-making tasks with equally legitimate options should only be solved using processes that trade off the positive and negative aspects (Eggert \& Bögeholz, 2006; Seethaler \& Linn, 2004; Siegel, 2006). However, not all decision-making tasks have equally legitimate options. If possible solutions concerning sustainable development do not reach a minimum threshold in terms of ecological, social or economic attributes a non-compensatory or mixed strategy should be used. In conclusion, different types of decision-making tasks demand different decision-making strategies to solve the conflict adequately. 
It should be stated that, in this context, the elimination of inadequate options is not seen as a simplification of the decision-making task, but meets the requirements of the framework of sustainable development.

During the decision-making process, personal values are taken into account in an explicit or implicit way (Bell \& Lederman, 2003; Grace \& Ratcliffe, 2002; Kolstø, 2006; Sadler \& Zeidler, 2004). Seethaler and Linn (2004) found that students listed benefits and drawbacks, but did not state why advantages could outweigh disadvantages. Hence, Seethaler and Linn (2004) conclude that this weighing of evidence should be made explicit in the students' decisions. In contrast, Jiménez-Aleixandre and PereiroMuñoz (2002) found that $11^{\text {th }}$-grade students considered a value hierarchy of environmental and economic aspects in their discussions. The consideration of values is included in both classical and more recently developed decision-making models (e.g., through a weighting factor in compensatory strategies or as a hierarchy of values used to eliminate options).

\section{Decision-Making Competence}

One crucial competence in the field of education for sustainable development is participation in decision-making processes (de Haan, 2010; Eggert \& Bögeholz, 2006). Students should be able to cope with multi-criteria decision-making situations that include competing objectives of sustainable development. Because it is not appropriate for teachers to judge their students' opinions, the focus should be on the students' reasoning in reaching their conclusions (Ratcliffe \& Grace, 2003). 
The main theoretical model upon which this study is based is the model of decision-making competence in situations related to sustainable development by Eggert and Bögeholz (2006; Bögeholz, 2011). Central aspects of the selection process were derived from a metamodel of decision-making by Betsch and Haberstroh (2005). In the first instance, the decision-maker gathers information regarding the three domains of sustainable development (ecological, social and economic domain) to describe the decision-making situation and generate possible options. The characteristics and consequences of each option are explicitly described according to relevant criteria. Once the possible options are generated, the decision-maker considers evidence for and against each option to reach their conclusions. This process may involve the implicit or explicit use of a choice rule. However, complex decision-making situations are cognitively demanding because large amounts of information and personal values have to be considered at the same time to make a trade-off. This study focuses on the judgment of different options and the way to reach a final decision. With respect to the goal of this study, this model is the most suitable as it provides a detailed framework that focuses on the decision-making process and education for sustainable development.

Previously, intervention studies have concentrated on the improvement of tradeoff-processes (Eggert, Bögeholz, Watermann \& Hasselhorn, in press; Seethaler \& Linn, 2004; Siegel, 2006; Roberts, Wilson \& Draney, 1997 [SEPUP]). Seethaler and Linn (2004) showed that students significantly improved in their consideration of supporting evidence and counter-evidence after working with a web-based curriculum on genetically modified food, which scaffolds students in gathering evidence in favour of 
and against their own position. However, in the final conclusion students encountered difficulties explaining why the evidence in favour outweighed the evidence against their position. Therefore, future research should focus on the inclusion of evidence for and against all available options, as well as how to weigh this evidence.

Ratcliffe (1997) found that structuring the decision-making process enabled students to identify relevant criteria of the decision-making task and discuss benefits and drawbacks in detail. Students followed a six step guideline of decision-making processes. First, students were asked to list options, list the relevant criteria and gather information. Then, students evaluated the advantages and disadvantages and arrived at a conclusion. The conclusion was finally reviewed with reflection on the decision-making process. Although students did not employ all aspects of the decision-making framework and did not discuss opposing positions systematically, they considered this structure to be helpful during the decision-making process.

Eggert et al. (in press) investigated the influence of training in compensatory decision-making and a combination of the compensatory approach with metacognitive structuring. All students $\left(7^{\text {th }}\right.$ grade) dealt with decision-making tasks concerning sustainability issues in a cooperative learning environment. In both treatment groups (compensatory decision-making and a combination of compensatory decision-making and metacognitive structuring), students' competence levels increased significantly from the pre-test to the post-test, although the metacognitive structuring did not have an additional effect.

In other disciplines such as business, medicine and the military, the teaching of decision-making has been investigated to a greater extent. Baron (1994) claims that the 
study of decision-making strategies may help avoid flaws in decision-making, such as the failure to consider all future consequences, alternative options and evidence.

In conclusion, there already exists a degree of successful training in decisionmaking. However, one central research gap remains: how students can be trained to make more systematic decisions with regard to sustainable development. If decisionmaking strategies, which are considered valuable in other disciplines, have a positive impact on decision-making competence when resolving socioscientific issues has only been investigated with regard to compensatory decision-making (Eggert et al., in press). The use of different strategies has not yet been addressed in intervention studies.

\section{Metadecision and Self-Regulated Learning}

How can students resolve socioscientific issues autonomously and thus become reflective and participatory citizens? Generally, they should be prepared to analyse the conflict in a socioscientific issue and reflect on an appropriate method to resolve it. One approach is the application of a decision-making strategy. To determine the most appropriate strategy the decision problem, the environment of the decision and the characteristics of the decision-maker have to be taken into account (Beach, 1990; Beach \& Mitchell, 1978). The complexity of these factors, which influence the selection of a decision-making strategy, require metadecision skills to resolve the conflict adequately (Beach, 1990). Therefore, decision-making involves not only the application of a decision-making strategy as a cognitive process but also the selection of an appropriate decision-making strategy as a metacognitive process. 
The way that students could approach such decision-making tasks in science classes can be embedded in the concept of self-regulated learning. The resolution of a socioscientific issue can be considered a learning task in which the metacognitive reflection of the underlying processes may enhance the quality of the decision, and experiences with previous decision-making tasks can affect the success of future tasks. Self-regulated learning is considered a dynamic process that integrates cognitive, metacognitive and motivational aspects of learning (Boekaerts, 1999; Zimmerman, 2000). Therefore, it provides a useful framework for the demands of the selection and application of decision-making strategies.

According to Zimmerman (2000), the process of performing a specific task has three phases: forethought, performance and self-reflection. Before beginning a task, self-regulated learners analyse the underlying task and select strategies to deal with it. During the task performance, learners observe and control the process. Afterwards, they reflect on their performance.

This sequence can be applied to the task of resolving socioscientific issues. First, a thorough task analysis is conducted prior to selecting an appropriate decision-making strategy. The decision-making situation should be analysed with the sustainability framework in mind. Do the advantages and disadvantages compensate for one another? Or, do the knockout criteria exist, which imply the exclusion of options? Second, the selected strategy is applied to resolve the issue. Finally, the performance and adequacy of the applied strategy are reflected upon. 


\section{Self-Determination Theory}

According to the self-determination theory (Deci \& Ryan, 1985, 2002), motivation and performance are best supported when learning environments satisfy three basic psychological needs: perceived competence, perceived autonomy and relatedness. Therefore, a setting that offers choices as well as possibilities to self-regulate the learning process, and that lets the learner experience competence in fulfilling a task, should increase motivation and thereby optimise performance. Moreover, in the field of socioscientific issues, a high degree of self-determination would not only be supportive in terms of motivation but would also represent a requirement of education for citizenship and environmental education, as students should be enabled to make decisions autonomously (Darner, 2009). Whether decision-making strategies help students acquire a higher level of competence and autonomy when dealing with socioscientific issues has not yet been investigated.

\section{Research Questions}

Although the decision of a course of action is a core component of resolving socioscientific issues, little research has been done with regard to the enhancement of the decision-making process itself. Thus, the present study is an attempt to uncover results from behavioural decision research that will be useful for science education. It was investigated, whether the application of decision-making strategies aids students in structuring their decision-making process and thereby increases their level of decisionmaking competence. The main hypothesis is as follows: 
1. Training in decision-making strategies enhances decision-making competence.

In addition, it was investigated how metadecision aids help students in their selection of adequate decision-making strategies. In accordance with the model of self-regulated learning by Zimmerman (2000), a task analysis was included in the intervention to aid the selection of an appropriate decision-making strategy. The task analysis should induce metacognitive reflection. The second hypothesis is as follows:

2. The combination of training in decision-making strategies and an explicit task analysis enhances decision-making competence at a higher rate.

Moreover, the effect of using decision-making strategies on motivational aspects such as perceived choice and perceived competence was examined. A positive effect would support the approach of training in decision-making strategies as compared to unstructured decisions. Especially for the training unit that involves elements of selfregulated learning a higher level of perceived autonomy is expected.

3. The self-determined use of decision-making strategies when resolving a socioscientific issue enhances perceived competence and perceived autonomy.

In order to investigate these hypotheses, a computer-based training programme that focused on three decision-making strategies was designed. 


\section{Methods}

Description of the Training Programme

[Insert Figure 1 about here]

All participating students dealt with complex decision-making tasks related to sustainable development. These tasks were embedded in a web-based training programme (see Figure 1). Generally, competencies are acquired best when applied to a specific context. Therefore, contexts were selected that are suitable for the application of each decision-making strategy. These contexts include political measures about the preservation of ecosystems (coral reefs and limnological ecosystems), the planning of land use after the mining of brown coal in Germany and consumer decisions. Therefore, local actions related to the students' lives as well as global consequences were incorporated, as these are essential aspects of education for sustainable development. Competing objectives were inherent in all contexts. Groups that would be affected by the result of the decision had to be considered. These groups included proprietors of diving schools close to endangered coral reefs, the workers in a production chain who depend on fair working conditions and the local population. In addition, the conservation of biodiversity and economic constraints had to be contrasted with these social considerations and integrated into the students' decisions.

All tasks required thorough information processing. The given information had to be evaluated to finally decide upon one of the possible options. To scaffold the decisionmaking process, tools for the application of three different decision-making strategies were included in the training programme. 
In the first session (45 minutes) students from both training groups learned how to apply a compensatory strategy (complete trade-off), a non-compensatory strategy (identification of knockout criteria and elimination of options) and a mixture of both (exclusion of unacceptable options followed by a trade-off of the remaining options). The use of these decision-making strategies was scaffolded in different ways. For the compensatory strategy, students applied the weighted-additive-value strategy (Jungermann et al., 2005; Payne et al., 1998) by converting advantages and disadvantages into positive and negative scores. Furthermore, all criteria had to be weighted to prioritise the underlying values. The non-compensatory strategy was applied with buttons that allowed the students to systematically eliminate options that had unacceptable traits, starting with the most important criterion, followed by the second most important one, and so forth to induce the hierarchization of personal values. Under this strategy, the programme followed the steps of an elimination-byaspects rule (Jungermann et al., 2005; Payne et al., 1998). Special attention was paid to the three domains of sustainable development to help students to decide which options were unacceptable with regard to these criteria. The third strategy was based on Beach's image theory (Beach, 1990; Beach \& Mitchell, 1978) and was implemented using a combination of the other two strategies. All tasks offered an opportunity to reflect on the use of these strategies.

In the second session (45 minutes) students applied these strategies to three new contexts in which they were required to select the strategy that best fits the type of the task. 
The first session was identical for both training groups (see Figure 1). In session 2, however, an element of self-regulated learning was integrated into the version for the second training group. Students in the second training group were asked to conduct an explicit task analysis in which they reflected upon the fit of the type of the decision-making task and the decision-making strategy. This required the use of metadecision skills.

The control group dealt with the same issues, but received additional ecological information instead of training in decision-making strategies.

Research Design

\section{[Insert Figure 2 about here]}

The effects of the computer-based training programme were examined in a prepost-follow-up control-group design (Figure 2) using the questionnaire of Eggert and Bögeholz (2010) at all measurement times. The pre-test and the first part of the training programme took place in a 90-minute block. During a second 90-minute block, which was carried out within a week of the first block, students completed the second part of the training programme and the post-test. The follow-up test was conducted three months after the intervention. At the beginning of the training programme, all participating students were randomly assigned to two different training groups and a control group by the computer programme. All of the groups were present in each classroom at the same time and each student was provided with a computer. 
Sample

The study was conducted in 25 biology courses at five different German high schools. A total of 386 students from grades $11-13$ took part in the training programme as well as pre-test and post-test (training group 1: 126, training group 2: 137, control group: 123). A total of 279 students took part in all three tests. Out of the 386 students, 154 were male and 226 were female (there were 6 missing values). The average age was 17.3 years. The two training groups and the control group did not differ significantly in terms of age, sex, previous biology grades, level of biology course or number of biology classes per week.

\section{Assessment of Decision-Making Competence}

The effects of this training programme were measured with a 45 -minute paperand-pencil test on decision-making competence (Eggert \& Bögeholz, 2010; Eggert et al., in press). The test consisted of two different types of tasks. In the first section of the questionnaire, students were asked to compare different options in two real-world situations concerning sustainable development. Students had to decide upon the most suitable option according to their individual preferences and explain in detail how they reached their decision. In the second section of the questionnaire, students were asked to reflect upon the decision-making processes of others in a third context. In this section, the decisions of three people were presented and students had to describe their way of reasoning and give advice on how these decision-making processes could be optimised. 
All of the chosen contexts in this test instrument belonged to a group of situations in which all options were considered equally legitimate according to the sustainability framework. Thus, a compensatory strategy is assumed to fit best, which requires a complete trade-off process.

The open answers were scored on 15 items (see Table 1; Eggert et al., in press; Eggert \& Bögeholz, 2010). Regarding the students' own decision-making process, two items indicate response behaviour for the chosen options and six items for the rejected options. In addition, the weighting of criteria according to individual preferences is included. The scale consists of dichotomous and polytomous items and therefore items have different maximum scores. The items indicating the response behaviour for the chosen and rejected options were weighted $2 / 3$, and the items indicating the weighting of criteria were weighted $1 / 3$. This takes into account that the number of items for the description of options was far larger than the number of items indicating the weighting of criteria. Furthermore, this ratio was chosen to maintain comparability with the study of Eggert and Bögeholz (2010).

Regarding the reflection on the decision-making processes of others, three items address the description of the presented decision-making strategies and two items address the suggestions for improvement (see Table 1). The items indicated whether students described the decisions and offered suggestions on a content level or provided strategic aspects (i.e. focused on the underlying decision-making strategies).

[Insert Table 1 about here]

Eggert and Bögeholz (2010) analysed the quality of the questionnaire with data from students in grades 6-12 $(N=436)$ and showed that the Rasch partial credit model 
best describes the decision-making competence of the investigated sample. According to their analyses, the instrument provides an adequate way to analyse decision-making competence in terms of item separation reliability, person separation reliability and construct validity. The education level of the student had a significant influence on decision-making. In addition, there was a significant correlation between decisionmaking competence and grades in the students' first language (German). In the standards and curricula of German as a subject argumentation plays an important role, which supports the validity of the questionnaire. Furthermore, decision-making can be distinguished from general cognitive abilities (ibid.). Eggert et al. (in press) used this questionnaire with a slightly modified scoring system in an intervention study with seventh graders. They demonstrated that this questionnaire was suitable for studies with repeated measurements.

In this study, analyses of covariance of the post-test/follow-up results as the dependent variables were conducted with the pre-test scores as a covariate. Reliability was calculated using Cronbach's alpha. For the dependent variables of the decisionmaking scale (post-test and follow-up test scores), Cronbach's alpha was .63 and .65, respectively. For the reflection scale, the internal consistency was lower (.62 and .52 for the post-test and follow-up test, respectively). Therefore, the students' responses were analysed on the item level with non-parametric tests. In this study, $50 \%$ of all questionnaires were coded by a second person. The interrater reliability (Cohen's kappa) was good (.81). After determining this value all items with different scores were discussed by the two raters so that they could agree upon a final score. 
For motivational reasons, different contexts were used in the questionnaire before and after the treatment. The questionnaires were structured and scored in the same way but they contained different topics. The post-test and follow-up test comprised the tasks used in Eggert and Bögeholz (2010) and Eggert et al. (in press). Due to the different contexts of the questionnaire, which may lead to varying levels of difficulty, the data from the control group were $z$-standardised for each measurement time to provide a baseline that was identical for all tests. The raw data of the training groups were then transformed according to the means and standard deviations of the control group.

For the analyses on the item level, it was determined whether students improved (gained a higher score) in the post-test/follow-up test compared to the pre-test results (score 1) or whether the score remained constant or decreased (score 0). The training groups and the control group were compared pairwise using $2 \times 2$ (group $x$ change of score) chi square analyses.

\section{Assessment of Intrinsic Motivation}

At the end of the training programme, students were asked to complete a 12-item intrinsic motivation questionnaire. This was a short version of the intrinsic motivation inventory (University of Rochester, 1996) that had been translated into German and pretested by Krombass and Harms (2006) and Wilde, Bätz, Kovaleva and Urhahne (2009). The questionnaire consisted of four subscales with three items each. Students self-reported their subjective interest/enjoyment, perceived competence, perceived choice and pressure/tension on a five-level Likert scale. Reliability (Cronbach's alpha) was good for all subscales: .83, .83, .84 and .73. Perceived competence and perceived 
TRAINING DECISION-MAKING STRATEGIES

choice (autonomy) are positive predictors of intrinsic motivation and pressure/tension is a negative predictor (University of Rochester, 1996). Differences between the groups were calculated using ANOVA and $t$-tests.

\section{Results}

\section{Decision-Making}

Figure 3 shows the mean $z$-standardised values for the pre-test, post-test and follow-up test for the two training groups (TG1 and TG2) and the control group (CG). Missing data were excluded listwise. In the pre-test, the training groups and the control group did not differ significantly.

\section{[Insert Figure 3 about here]}

The analysis of covariance of the post-test results with pre-test scores as a covariate did not show significant differences between the training groups and the control group. However, in the long run, the treatment did have a significant effect. Comparing the follow-up results of TG1 and the CG in a pairwise ANCOVA, the effect of the group after controlling for the effect of the pre-test result was found to be $F_{(1,162)}=12.8, p<.001$, partial $\eta^{2}=.074$. Comparing TG2 and the CG, the effect of the group was $F_{(1,177)}=13.2, p<.001$, partial $\eta^{2}=.070$. TG1 and TG2 did not differ significantly.

To gain further insight into the effects of the training programme, the weighting of criteria according to personal values and the way students dealt with advantages and disadvantages will be presented on the item level. Looking at the development from the 
pre-test to the post-test, students from TG1 and TG2 improved significantly more frequently in weighting criteria than students from the CG (TG1-CG: $\chi^{2}=8.0, d f=1$, $p<.01$; TG2-CG: $\chi^{2}=7.7, d f=1, p<.01$ ). This effect was even stronger in the long run (pre-test to follow-up: TG1-CG: $\chi^{2}=17.0, d f=1, p<.001$; TG2-CG: $\chi^{2}=20.2, d f=1$, $p<.001)$. The training groups did not differ significantly.

However, the way students supported their claims by stating benefits and drawbacks of each option did not improve after the training and decreased slightly from the pre-test to the post-test. Furthermore, students in the training groups tended to identify fewer advantages and disadvantages than the control group.

\section{Reflection}

\section{[Insert Table 2 about here]}

In Table 2, the observed and expected absolute frequencies of an increase versus a constancy or decrease of the scores from the pre-test to the post-test are presented. An increase of the score indicates a shift from content-based descriptions and suggestions to responses involving strategic aspects of the decision-making process.

Regarding the description of the presented non-compensatory decision, the gains of the training groups were highly significant when compared to the control group: TG1CG: $\chi^{2}=36.2, d f=1, p<.001 ;$ TG2-CG: $\chi^{2}=36.1, d f=1, p<.001$. The quality of the description of the compensatory decision-making process also improved as a result of the training: TG1-CG: $\chi^{2}=19.8, d f=1, p<.001 ;$ TG2-CG: $\chi^{2}=16.0, d f=1, p<.001$. Furthermore, the scores regarding the suggestions that students made to improve the 
presented intuitive decision-making process increased significantly in TG2 as compared to TG1 and the CG: TG2-TG1: $\chi^{2}=5.9, d f=1, p<.05$; TG2-CG: $\chi^{2}=6.9, d f=1, p<.01$. However, no significant changes were found for the remaining two items, the description of the intuitive decision-making process and suggestions to improve the compensatory decision (not documented in Table 2).

Regarding the changes from the pre-test to the follow-up test, an improvement in the scores could only be seen for one item, the suggestions for the improvement of the intuitive decision (not documented in Table 2): TG2-TG1: $\chi^{2}=5.6, d f=1, p<.05$; TG2CG: $\chi^{2}=4.2, d f=1, p<.05$. TG1 and the CG did not differ significantly. In conclusion, only the training group that was stimulated to conduct an initial task analysis as an aspect of self-regulated learning experienced a long-run increase in the test scores regarding the reflection of the decision-making processes of others.

\section{Intrinsic Motivation}

Table 3 presents the means and standard deviations of the four scales related to intrinsic motivation during the training programme.

\section{[Insert Table 3 about here]}

With regard to interest/enjoyment, perceived competence and pressure/tension, the groups did not differ significantly. However, the perceived choice during the training programme was significantly higher for TG2 compared to the CG $\left(t_{(242)}=2.63, p<.01\right.$, $r=.17)$. Comparing $T G 1$ to the $C G$ and $T G 1$ to $T G 2$, no significant differences were found. 


\section{Conclusions}

In this intervention study, it was investigated whether training in decision-making strategies fosters decision-making competence when resolving socioscientific issues related to sustainable development. The results of the post-test and the follow-up test suggest that the strategic training enhanced the competence level. Considering the impact of the training programme on the students' own decision-making process, the significant difference in the follow-up test between each training group and the control group shows a satisfying result. The intervention triggered a development that could be identified three months later. However, in the short run, no increase in competence level could be found. Whilst students from both training groups improved more frequently in weighting criteria than the control group, they stated fewer advantages and disadvantages. Thus, positive and negative effects of the training were cancelled out in the short term analysis. One possible explanation could be that the training programme unintentionally triggered the use of non-compensatory strategies, where fewer aspects must be considered compared to a full trade-off. Students applied three different strategies in the learning programme, but only the compensatory approach is considered to be appropriate in the questionnaire, as no knockout criteria exist in the presented contexts according to the framework of sustainable development. Because the use of non-compensatory strategies is cognitively less demanding, students may have used this strategy more frequently than a compensatory strategy, especially in the post-test, which was administered right after the possibly tiring training programme.

Looking at the reflection of the decision-making processes of others, a significant improvement from the pre-test to the post-test was shown for both training groups with 
regard to several items. However, turning to the follow-up test, the effects of the training could only be demonstrated with respect to the suggestions for the improvement of the presented intuitive decision. As the training programme did not specifically focus on such a reflection task, this short term enhancement is quite plausible.

For the second hypothesis, only some supporting evidence could be found, as the differences between the two training groups were not significant with regard to the decision-making scale and most of the items concerning the reflection of decisionmaking processes. However, the integration of a task analysis as a metadecision aid, which was based on the concept of self-regulated learning, had an additional effect on one aspect of the reflection: the quality of suggestions to improve intuitive decisionmaking processes. This effect could be identified three months after the intervention. The finding that the differences between the two training groups were not significant for most aspects of decision-making competence can be explained by a deficit in producing the newly acquired metacognitive strategy of conducting a task analysis or an inefficient use due to the very short duration of the intervention (Hasselhorn \& Gold, 2006).

Regarding the third hypothesis, supporting evidence was uncovered. The combination of the decision-making training and self-regulatory elements had a positive effect on the perceived level of choice, as compared to the control group. The analysis of the decision-making task and the deliberate and reflected selection of a strategy to tackle the task helped students perceive more control over their actions when resolving the issue. This aligns with the assumptions of the self-regulation framework by Zimmerman (2000) and the self-determination theory by Deci and Ryan (1985, 2002). Self-regulation of the learning process should lead to a perceived internal locus of 
causality of one's actions and thus a higher degree of perceived autonomy and selfdetermination. Consequently, experiencing autonomy is valuable because autonomy is a positive predictor of intrinsic motivation. Moreover, perceived autonomy and selfdetermination when resolving socioscientific issues are useful for citizenship education and environmental education from a normative viewpoint (Darner, 2009). In conclusion, the combined training that induces a higher level of self-determination is more beneficial.

One aspect worth further consideration is the reliability of the decision-making questionnaire. For the analysed decision-making scale, Cronbach's alpha has acceptable values as one type of decision-making task was presented: decisions in which all options are considered equally legitimate according to the framework of sustainable development. However, regarding the students' own decision, those who prioritised criteria according to their personal values did not necessarily state all of the advantages and disadvantages because their prioritisation already implied reasons for choosing or rejecting one specific option. Those students who did not prioritise the underlying criteria tended to explain their choice by offering more advantages and disadvantages. However, both aspects belong to the same construct from a theoretical perspective (Eggert \& Bögeholz, 2006). Regarding the reflection of the decision-making processes of other people, students needed to describe a wide range of different decision-making strategies. Furthermore, making suggestions for the improvement and the description of the presented decisions are not equally difficult, but represent important aspects of the reflection regarding tasks with equally legitimate options. Due to the heterogeneity of this second construct, which covers a wide range of facets, the 
internal consistency (Cronbach's alpha) of the reflection was moderate. Therefore, the data were analysed on the item level rather than on the scale level.

A limitation of the study is that it cannot determine whether the level of competence of any group increased from the pre-test to subsequent measurement times because different contexts were used in the questionnaire at different points in time. Only differences in competence level of the training groups relative to the control group could be described.

However, considering the conservative choice of a control group, which also dealt with the same decision-making tasks during the intervention, and the very short time of the learning programme, the overall effects are quite compelling. Furthermore, the self-regulatory decision-making training led to higher levels of perceived choice than a decision-making environment without strategic training. Altogether, it can be concluded that systematic training in decision-making strategies, combined with a task analysis as an element of self-regulated learning, may be a suitable approach to foster elaborate reasoning.

One implication for the use of decision-making strategies in science classes is that the inappropriate and hasty exclusion of options should be addressed by teachers. From a normative viewpoint, a non-compensatory strategy should only be applied if knockout criteria exist according to the sustainability framework. However, it would not be appropriate to use it in order to avoid the cognitively demanding compensatory strategies. One approach would be to reflect upon another person's decision, where options are precipitately excluded without explicitly reflecting on the framework of sustainable development. According to Ratcliffe and Grace (2003), evaluating the 
decisions of others enables students to identify the strengths and weaknesses of their own reasoning. In this way, knowledge about decision-making strategies can be combined with a reflection to enhance the decision-making competence level. This should be further investigated in future studies.

In order to measure the effects of the use of decision-making strategies, students resolved the socioscientific issues individually. The impact of integrating these strategies into group discussion processes should be examined in future research. To what extent do collective negotiations of knockout criteria or thresholds, which may lead to the elimination of options, affect the students' decision-making competence? Moreover, scholars should determine whether small group or whole class discussions about the fit of certain decision-making strategies and types of decision-making situations lead to a deeper understanding of the underlying decision-making processes and thus a long-term gain in decision-making competence. Collective decision-making and discourse in the field of socioscientific issues are crucial in today's world (Zeidler et al., 2005). A next step would be to examine how to integrate personal decision-making skills such as the reflected use of decision-making strategies with classroom discourse. 


\section{References}

American Association for the Advancement of Science [AAAS] (1989). Science for all Americans. Washington: American Association for the Advancement of Science.

Arvai, J. L., Campbell, V. E. A., Baird, A., \& Rivers, L. (2004). Teaching students to make better decisions about the environment: lessons from the decision sciences. The Journal of Environmental Education, 36(1), 33-44.

Baron, J. (1994). Thinking and deciding (2nd ed.). Cambridge: Cambridge University Press.

Baron, J. (1998). Judgment misguided: Intuition and error in public decision making. New York: Oxford University Press.

Beach, L. R. (1990). Image theory: Decision making in personal and organizational contexts. West Sussex, England: John Wiley and Sons.

Beach, L. R., \& Mitchell, T. R. (1978). A contingency model for the selection of decision strategies. Academy of Management Review, 3(3), 439-449.

Bell, R. L., \& Lederman, N. G. (2003). Understandings of the Nature of Science and Decision Making on Science an Technology Based Issues. Science Education, 87(3), 352-377.

Betsch, T., \& Haberstroh, S. (2005). Current research on routine decision making: Advances and prospects. In T. Betsch \& S. Haberstroh (Eds.), The routines of decision making (pp. 359-376). Mahwah, NJ: Erlbaum.

Boekaerts, M. (1999). Self-regulated learning: Where we are today. International Journal of Educational Research, 31, 445-457. 
Bögeholz, S. (2011). Bewertungskompetenz im Kontext Nachhaltiger Entwicklung: Ein Forschungsprogramm [Decision-making competence in the context of sustainable development. A research programme]. In D. Höttecke (Ed.), Naturwissenschaftliche Bildung als Beitrag zur Gestaltung partizipativer Demokratie. Gesellschaft für Didaktik der Chemie und Physik. Jahrestagung in Potsdam 2010 (pp. 32-46). Münster, Germany: LIT-Verlag.

Bögeholz, S., \& Barkmann, J. (2005). Rational choice and beyond: Handlungsorientierende Kompetenzen für den Umgang mit faktischer und ethischer Komplexität [Rational choice and beyond: Action-oriented competencies for dealing with factual and ethical complexity]. In R. Klee, A. Sandmann, \& H. Vogt (Eds.), Lehrund Lernforschung in der Biologiedidaktik (Vol. 2, pp. 211-224). Insbruck, Austria: Studienverlag.

Bögeholz, S., Hößle, C., Langlet, J., Sander, E., \& Schlüter, K. (2004). Bewerten Urteilen - Entscheiden im biologischen Kontext: Modelle in der Biologiedidaktik [Evaluating - Judging - Deciding in a biological context: Models in the didactics of biology]. Zeitschrift für Didaktik der Naturwissenschaften, 10, 89-115.

Darner, R. (2009). Self-determination theory as a guide to fostering environmental motivation. The Journal of Environmental Education, 40(2), 39-49.

de Haan, G. (2010). The development of ESD-related competencies in supportive institutional frameworks. International Review of Education, 56(2-3), 315-328.

Deci, E. L., \& Ryan, R. M. (1985). Intrinsic motivation and self-determination in human behavior. New York, NY: Plenum Press. 
Deci, E. L., \& Ryan, R. M. (2002). Handbook of self-determination research. Rochester, NY: Univ. of Rochester Press.

Driver, R., Newton, P., \& Osborne, J. (2000). Establishing the norms of scientific argumentation in classrooms. Science Education, 84(3), 287-312.

Eggert, S., \& Bögeholz, S. (2006). Göttinger Modell der Bewertungskompetenz Teilkompetenz „Bewerten, Entscheiden und Reflektieren“ für Gestaltungsaufgaben Nachhaltiger Entwicklung. [Göttingen's model of decisionmaking competence - subcompetence „evaluating, deciding and reflecting“ on tasks related to sustainable development.] Zeitschrift für Didaktik der Naturwissenschaften, 12, 177-199.

Eggert, S., \& Bögeholz, S. (2010). Students' use of decision-making strategies with regard to socioscientific issues: An application of the Rasch partial credit model. Science Education, 94, 230-258.

Eggert, S., Bögeholz, S., Watermann, R., \& Hasselhorn, M. (in press). Förderung von Bewertungskompetenz im Biologieunterricht durch zusätzliche metakognitive Strukturierungshilfen beim Kooperativen Lernen - Ein Beispiel für Veränderungsmessungen [Fostering decision-making competence in biology classes through addidtional metacognitive structuring in cooperative learning environments. An example for the assessment of intervention effects]. Zeitschrift für Didaktik der Naturwissenschaften.

Grace, M., \& Ratcliffe, M. (2002). The science and values that young people draw upon to make decisions about biological conservation issues. International Journal of Science Education, 24(11), 1157-1169. 
Haidt, J. (2001). The emotional dog and its rational tail: A social intuitionist approach to moral judgment. Psychological Review, 108(4), 814-834.

Hasselhorn, M., \& Gold, A. (2006). Pädagogische Psychologie [Educational psychology]. Stuttgart, Germany: Kohlhammer.

Huckle, J., \& Sterling, S. (1996). Education for sustainability. London: Earthscan.

Jiménez-Aleixandre, M., \& Pereiro-Muñoz, C. (2002). Knowledge producers or knowledge consumers? Argumentation and decision making about environmental management. International Journal of Science Education, 24, $1171-1190$.

Jungermann, H., Pfister, H., \& Fischer, K. (2005). Die Psychologie der Entscheidung [The psychology of decisions] (2nd ed.). Heidelberg, Germany: Elsevier, Spektrum, Akademischer Verlag.

Kultusministerkonferenz [KMK] (2005). Bildungsstandards im Fach Biologie für den Mittleren Schulabschluss [Standards in biology for the middle-school graduation]. München, Germany: Wolters Kluwer Deutschland.

Kultusministerkonferenz $[\mathrm{KMK}], \&$ Bundesministeriums für wirtschaftliche Zusammenarbeit und Entwicklung [BMZ] (2007). Orientierungsrahmen für den Lernbereich Globale Entwicklung im Rahmen einer Bildung für nachhaltige Entwicklung [Reference frame for the learning field of global development within the framework of education for sustainable development]. Bonn, Germany.

Kolstø, S. D. (2001). Scientific literacy for citizenship: Tools for dealing with the science dimension of controversial socioscientific issues. Science Education, 85(3), 291310. 
Krombass, A., \& Harms, U. (2006). Ein computergestütztes Informationssystem zur Biodiversität als motivierende und lernförderliche Ergänzung der Exponate eines Naturkundemuseums [A computer-based information system about biodiversity as a motivating and learning promoting supplement for the exhibits of a museum of natural history]. Zeitschrift für Didaktik der Naturwissenschaften, 12, 7-22.

Kuhn, D. (1991). The skills of argument. New York: Cambridge University Press.

National Research Council [NRC] (1996). National science education standards. Washington, DC: National Academy Press.

Payne, J., Bettmann, J. R., \& Luce, M. F. (1998). Behavioral decision research: An overview. In M. H. Birnbaum (Eds.), Measurement, judgment, and decision making (2nd ed., pp. 303-359). San Diego, CA: Academic Press.

Pedretti, E. (2003). Teaching science, technology, society and environment (STSE) education. In D. L. Zeidler (Ed.), The role of moral reasoning on socioscientific issues and discourse in science education (pp. 219-239). Dordrecht: Kluwer Academic Publ.

Qualifications and Curriculum Authority [QCA] (2004). Science national curriculum for England. London, England: QCA.

Ratcliffe, M. (1997). Pupil decision-making about socioscientific issues within the science curriculum. International Journal of Science Education, 19(2), 167-182.

Ratcliffe, M., \& Grace, M. (2003). Science education for citizenship - Teaching socioscientific issues. Maidenhead: Open University Press.

Roberts, L., Wilson, M., \& Draney, K. (1997). The SEPUP assessment system: An overview. BEAR Report Series, SA-97-1. Berkeley, CA: University of California. 
Sadler, T. D. (2004). Informal reasoning regarding socioscientific issues: A critical review of research. Journal of Research in Science Teaching, 41, 513-536.

Sadler, T. D., \& Zeidler, D. L. (2004). The morality of socioscientific issues: Construal and resolution of genetic engineering dilemmas. Science Education, 88(1), 4-27.

Sadler, T. D., \& Zeidler, D. L. (2005). Patterns of informal reasoning in the context of socioscientific decision making. Journal of Research in Science Teaching, 42(1), 112-138.

Sauvé, L. (1996). Environmental education and sustainable development: a further appraisal. Canadian Journal of Environmental Education, 1, 7-34.

Scott, W., \& Gough, S. (2003). Sustainable development and learning. London: RoutledgeFalmer.

Seethaler, S., \& Linn, M. (2004). Genetically modified food in perspective: An inquirybased curriculum to help middle school students make sense of tradeoffs. International Journal of Science Education, 26, 1765-1785.

Siegel, M. A. (2006). High school students' decision making about sustainability. Environmental Education Research, 12(2), 210-215.

United Nations Conference on Environment and Development [UNCED] (1992). Rio Declaration on Environment and Development. Retrieved January 20, 2011, from http://www.un.org/documents/ga/conf151/aconf15126-1annex1.htm.

University of Rochester (1996). Intrinsic motivation inventory. Retrieved December 9, 2008, from http://www.psych.rochester.edu/SDT/measures/IMI_scales.php. 
Wilde, M., Bätz, K., Kovaleva, A., \& Urhahne, D. (2009). Überprüfung einer Kurzskala intrinsischer Motivation (KIM) [Review of a short scale for intrinsic motivation]. Zeitschrift für Didaktik der Naturwissenschaften, 15, 31-45.

Zeidler, D. L., Sadler, T. D., Simmons, M. L., \& Howes, E. V. (2005). Beyond STS: A research-based framework for socioscientific issues education. Science Education, 89, 357-377.

Zeidler, D. L. (1997). The central role of fallacious thinking in science education. Science Education, 81(1), 483-496.

Zeidler, D. L., \& Sadler, T. D. (2007). The role of moral reasoning in argumentation: Conscience, character, and care. In S. Erduran \& M. Jiménez-Aleixandre (Eds.), Argumentation in Science Education (pp. 201-216). Dordrecht, The Netherlands: Springer.

Zimmerman, B. J. (2000). Attaining self-regulation: A social cognitive perspective. In M. Boekaerts (Ed.), Handbook of Self-Regulation (pp. 13-39). Burlington, MA: Elsevier Academic Press.

Zohar, A., \& Nemet, F. (2002). Fostering students' knowledge and argumentation skills through dilemmas in human genetics. Journal of Research in Science Teaching, 39(1), 35-62. 


\section{Acknowledgements}

This study was conducted with the support of the German Research Foundation (Deutsche Forschungsgemeinschaft) and its graduate research programme 1195 Understanding and Enhancing Educational Fit in Schools. The authors thank Christian Rolfes for his excellent technical support during the development of the web-based training programme, all members of the graduate research programme as well as the institute for didactics of biology in Göttingen for the enriching discussions and Dr. Wolfang Woerner for his valuable advice on statistical issues. 
Table 1

Scoring guide for the assessment of decision-making competence

\begin{tabular}{|c|c|c|c|c|c|c|}
\hline No. & $\begin{array}{l}\text { Item } \\
\text { description }\end{array}$ & Score 0 & Score 1 & Score 2 & Score 3 & Score 4 \\
\hline \multicolumn{7}{|c|}{ Decision-making } \\
\hline $1+6$ & $\begin{array}{l}\text { Chosen } \\
\text { option }\end{array}$ & $\begin{array}{l}\text { Does not } \\
\text { state } \\
\text { anything }\end{array}$ & $\begin{array}{l}\text { States only } \\
\text { positive } \\
\text { aspects }\end{array}$ & $\begin{array}{l}\text { States } \\
\text { positive } \\
\text { and } \\
\text { negative } \\
\text { aspects }\end{array}$ & & \\
\hline $\begin{array}{l}2,3,4 \\
+ \\
7,8,9\end{array}$ & $\begin{array}{l}\text { Rejected } \\
\text { options }\end{array}$ & $\begin{array}{l}\text { Does not } \\
\text { state } \\
\text { anything }\end{array}$ & $\begin{array}{l}\text { States only } \\
\text { negative } \\
\text { aspects }\end{array}$ & $\begin{array}{l}\text { States } \\
\text { positive } \\
\text { and } \\
\text { negative } \\
\text { aspects }\end{array}$ & & \\
\hline $5+10$ & $\begin{array}{l}\text { Weighting } \\
\text { criteria }\end{array}$ & $\begin{array}{l}\text { Does not } \\
\text { explicitly } \\
\text { weight } \\
\text { criteria }\end{array}$ & $\begin{array}{l}\text { Weights } \\
\text { criteria } \\
\text { explicitly }\end{array}$ & & & \\
\hline
\end{tabular}

Reflection

\section{Description of Does not non- compensatory decision- making respond to the task}

12 Description of compensatory decisionmaking

13 Description of intuitive decisionmaking

14 Suggestions for improvement (intuitive decisionmaking)

15 Suggestions for improvement (compensatory decision-

Does not respond to the task

Does not Does not
respond to the task

Reference
only to
content

Reference to some aspects of strategy

Reference

\section{Reference} only to content

Reference only to content

No suggestions

\section{Sugges-} tions on content level

Reference to some aspects of strategy

Reference to some aspects of strategy

Suggestions on strategic level

No
suggestions

Sugges- Suggestions on tions on content strategic level level to all aspects of strategy

Score 3 and explains underlying conflict

Reference Reference to main to all aspects of aspects of strategy strategy Reference to all aspects of strategy making)

Note. Based on Eggert et al. (in press; cf. Eggert \& Bögeholz, 2010). 
Table 2

Reflection: Changes in the score from the pre-test to the post-test (observed and expected absolute frequencies)

\begin{tabular}{|c|c|c|c|c|}
\hline & $\begin{array}{c}\text { Training group } 1 \\
\text { obs. (exp.) }\end{array}$ & $\begin{array}{c}\text { Training group } 2 \\
\text { obs. (exp.) }\end{array}$ & $\begin{array}{c}\text { Control group } \\
\text { obs. (exp.) }\end{array}$ & Total \\
\hline \multicolumn{5}{|c|}{ Description of non-compensatory decision-making } \\
\hline \multirow[t]{2}{*}{ Increase } & 74 & 81 & 25 & 180 \\
\hline & $(59.5)$ & $(66.2)$ & $(54.4)$ & \\
\hline \multirow{2}{*}{ Constancy / decrease } & 42 & 48 & 81 & 171 \\
\hline & $(56.5)$ & $(62.8)$ & $(51.6)$ & \\
\hline Total & 116 & 129 & 106 & 351 \\
\hline \multicolumn{5}{|c|}{ Description of compensatory decision-making } \\
\hline \multicolumn{5}{|l|}{ Increase } \\
\hline & 70 & 73 & 32 & 175 \\
\hline & $(58.0)$ & $(64.5)$ & $(52.5)$ & \\
\hline \multicolumn{5}{|l|}{ Constancy / decrease } \\
\hline & 46 & 56 & 73 & 175 \\
\hline & $(58.0)$ & $(64.5)$ & $(52.5)$ & \\
\hline Total & 116 & 129 & 105 & 350 \\
\hline \multicolumn{5}{|c|}{ Suggestions for the improvement of intuitive decision-making } \\
\hline \multicolumn{5}{|l|}{ Increase } \\
\hline & 17 & 37 & 17 & 71 \\
\hline & $(21.7)$ & $(26.5)$ & $(22.8)$ & \\
\hline \multicolumn{5}{|l|}{ Constancy / decrease } \\
\hline & 61 & 58 & 65 & 184 \\
\hline & (56.3) & (68.5) & $(59.2)$ & \\
\hline Total & 78 & 95 & 82 & 255 \\
\hline
\end{tabular}




\section{Table 3}

Means and standard deviations of intrinsic motivation scales during the training programme (five-level Likert scale; 1-5)

\begin{tabular}{lcccccc}
\hline & \multicolumn{2}{c}{ Training group 1 } & \multicolumn{2}{c}{ Training group 2 } & \multicolumn{2}{c}{ Control group } \\
\hline & $M$ & $(S D)$ & $M$ & $(S D)$ & $M$ & $(S D)$ \\
Interest / enjoyment & 2.91 & $(0.80)$ & 2.91 & $(0.81)$ & 2.95 & $(0.79)$ \\
Perceived competence & 3.36 & $(0.78)$ & 3.22 & $(0.82)$ & 3.26 & $(0.64)$ \\
Perceived choice & 3.62 & $(0.87)$ & 3.74 & $(0.86)$ & 3.45 & $(0.88)$ \\
Pressure / tension & 2.07 & $(0.86)$ & 2.26 & $(0.90)$ & 2.16 & $(0.81)$ \\
\hline
\end{tabular}


Figure 1. Structure of the training programme $349 \times 156 \mathrm{~mm}$ (72 x 72 DPI)

URL: http://mc.manuscriptcentral.com/tsed Email: editor_ijse@hotmail.co.uk 


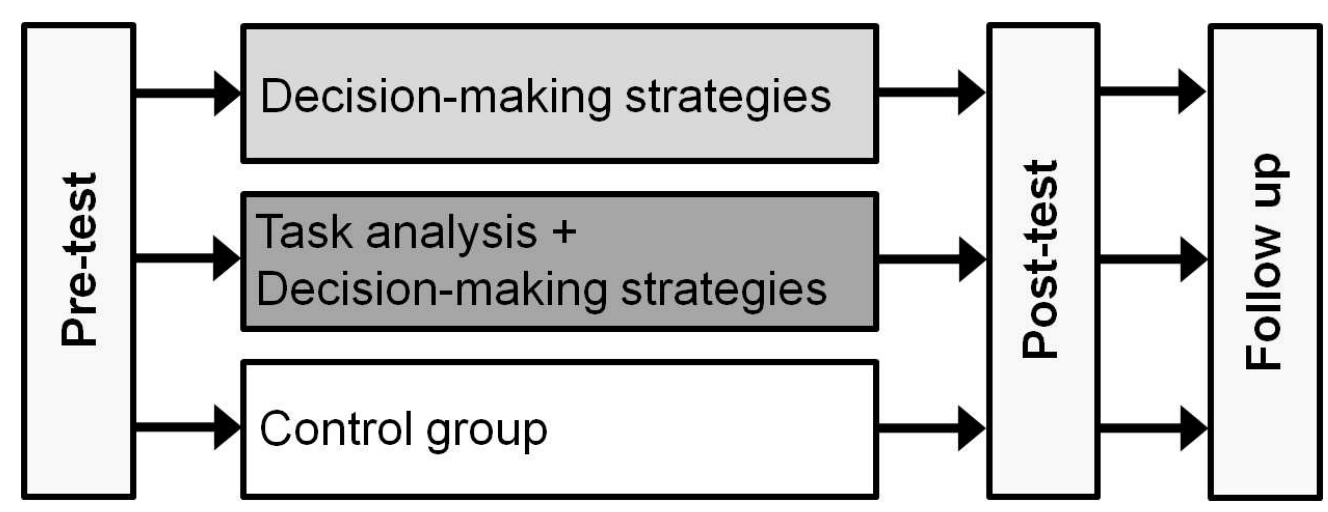

Figure 2. Research design $442 \times 163 \mathrm{~mm}(72 \times 72 \mathrm{DPI})$ 


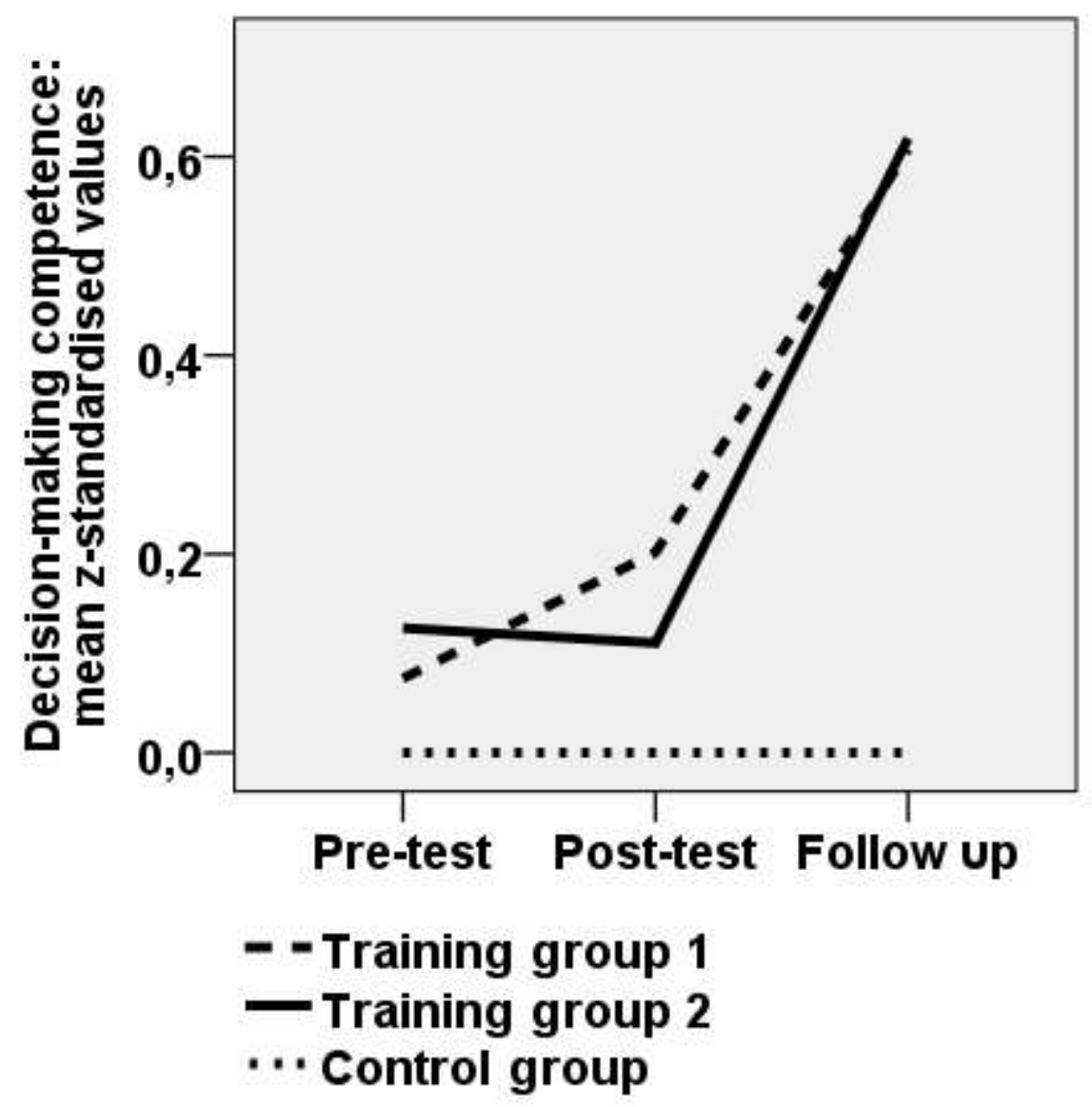

Figure 3. Mean values of decision-making competence ( $z$-standardised using mean and standard deviation of control group) $163 \times 164 \mathrm{~mm}(72 \times 72 \mathrm{DPI})$ 